\title{
Catecholamine-secreting carotid body paraganglioma: successful preoperative control of hypertension and clinical symptoms using high-dose long-acting octreotide
}

\author{
Omayma Elshafie', Yahya Al Badaai ${ }^{2}$, Khalifa Alwahaibi ${ }^{2}$, Asim Qureshi ${ }^{3}$, \\ Samir Hussein ${ }^{4}$, Faisal Al Azzri ${ }^{4}$, Ali Almamari ${ }^{1}$ and Nicholas Woodhouse ${ }^{1}$ \\ Departments of ${ }^{1}$ Medicine ${ }^{2}$ Surgery ${ }^{3}$ Pathology ${ }^{4}$ Radiology, Sultan Qaboos University Hospital, Muscat, \\ Sultanate of Oman
}

\author{
Correspondence \\ should be addressed \\ to O Elshafie \\ Email \\ omayma0@hotmail.com
}

\section{Summary}

A 48-year-old hypertensive and diabetic patient presented with a 10-year history of progressive right facial pain, tinnitus, hearing loss, sweating, and palpitations. Investigations revealed a $5.6 \mathrm{~cm}$ vascular tumor at the carotid bifurcation. Her blood pressure (BP) was 170/110, on lisinopril $20 \mathrm{mg}$ od and amlodipine $10 \mathrm{mg}$ od and $100 \mathrm{U}$ of insulin daily. A catecholaminesecreting carotid body paraganglioma (CSCBP) was suspected; the diagnosis was confirmed biochemically by determining plasma norepinephrine (NE) level, $89000 \mathrm{pmol} / \mathrm{l}$, and chromogranin A (CgA) level, $279 \mu \mathrm{g} / \mathrm{l}$. Meta-iodobenzylguanidine and octreotide scanning confirmed a single tumor in the neck. A week after giving the patient a trial of octreotide $100 \mu \mathrm{g} 8 \mathrm{~h}$, the NE level dropped progressively from 50000 to $25000 \mathrm{pmol} / \mathrm{l}$ and CgA from 279 to $25 \mu \mathrm{g} / \mathrm{l}$. Treatment was therefore continued with labetalol $200 \mathrm{mg}$ twice daily (bid) and long-acting octreotide-LA initially using $40 \mathrm{mg} / \mathrm{month}$ and later increasing to $80 \mathrm{mg} / \mathrm{month}$. On this dose and with a reduced labetalol intake of $100 \mathrm{mg}$ bid, BP was maintained at 130/70 and her symptoms resolved completely. $\mathrm{CgA}$ levels returned to normal in the first week and these were maintained throughout the 3 month treatment period. During tumor resection, there were minimal BP fluctuations during the $10 \mathrm{~h}$ procedure. We conclude that short-term high-dose octreotide-LA might prove valuable in the preoperative management of catecholaminesecreting tumors. To the best of our knowledge, this is the first report on the successful use of octreotide in a CSCBP.

\section{Learning points}

- The value of octreotide scanning in the localization of extra-adrenal pheochromocytoma.

- Control of catecholamine secretion using high-dose octreotide.

- This is a report of a rare cause of secondary diabetes and hypertension.

\section{Background}

Paranganglionomas (PGs) are found distributed throughout the autonomic nervous system. They consist of chief cells, of neural crest origin, which are capable of forming and secreting catecholamines. This occurs in tumours arising predominantly from the sympathetic rather than the \footnotetext{
\begin{tabular}{lll}
\hline OPEN & Access & This work is licensed under a Creative Commons \\
Attribution-NonCommercial-NoDerivs 3.0
\end{tabular} Unported License.
}

parasympathetic nervous system. Adrenal paraganglionomas, usually referred to as phaeochromocytomas, account for $90 \%$ of all such tumours, with only $10 \%$ being found outside the adrenal and no more than $3-4 \%$ of these being in the head and neck. Less than 5\% of head and neck PGs secrete catecholamines and as in all extraadrenal catecholamine 

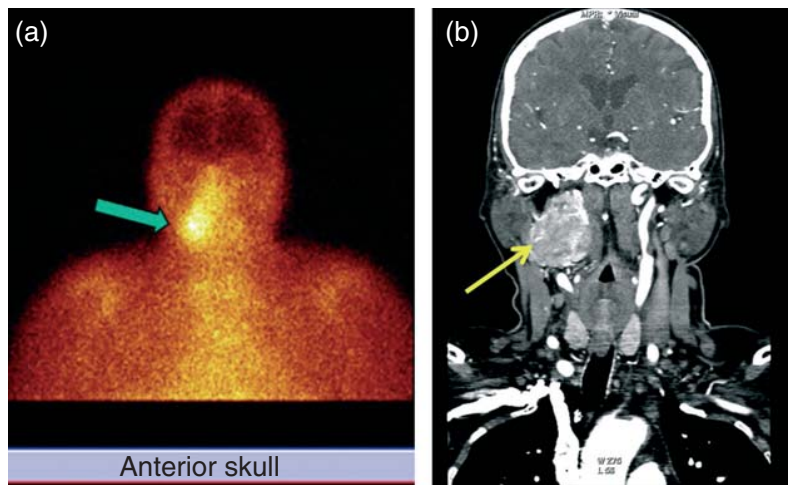

Figure 1

(a) CT of the head and neck showing a large vascular tumor sized $5.6 \times 5 \mathrm{~cm}$ extending from the base of skull to $\mathrm{C} 3$ and terminating just above the carotid bifurcation. (b) ${ }^{111} \mathrm{In}$-Octreotide scan showing a catecholaminesecreting carotid body paraganglioma.

secreting paraganglionomas (CSPs) they produce predominantly norepinephrine and little epinephrine. Their aetiology is unknown in most cases but about 25\% have mutations involving RET, VHL, TVF1, SDHB, SDHC or SDHD genes. The majority of these tumours can be localized by scanning with I-131 labelled MIBG, III In-octreotide or 18F-dopa positron emission tomography (1) (2) (3).

In this paper, we report a patient with a single carotid body catecholamine secreting paraganglionoma (CSP) in whom high dose octreotide produced a complete clinical and near complete biochemical remission. Her details are reported below.

\section{Case presentation}

A 48-year-old hypertensive and diabetic patient presented to another hospital with a 10-year history of progressive right facial pain, tinnitus, hearing loss, sweating, and palpitations. Investigations revealed a $5.5 \mathrm{~cm}$ tumor close to the carotid bifurcation (Fig. 1a). Her diabetes was poorly controlled although taking $100 \mathrm{U}$ of insulin daily (HbA1c, 10.8\%), and her blood pressure (BP) was 170/110 in spite of taking amlodipine $10 \mathrm{mg}$ daily and lisinopril $20 \mathrm{mg}$ daily. She was referred to our hospital for embolization where she was given a $\beta$-blocker in addition to her other medications; several hours later her BP increased to 240/130 and the procedure was cancelled. A pheochromocytoma was suspected.

\section{Investigation}

Her plasma norepinephrine (NE) level grossly elevated to $89000 \mathrm{pmol} / \mathrm{l}$ (normal value: 240-2400) and dopamine $6506 \mathrm{pmol} / \mathrm{l}$ (normal value: <475) with a low normal epinephrine level $39 \mathrm{pmol} / \mathrm{l}$ (normal value: <273). The chromogranin A (CgA) level was also raised $279 \mu \mathrm{g} / 1$ (normal range: 27-94). ${ }^{111}$ In-octreotide (Fig. 1a) and 131 meta-iodobenzylguanidine scanning revealed a solitary tumor in the right neck. CT scanning of the neck revealed a large right-sided vascular tumor extending from the base of the skull and terminating just above the carotid bifurcation (Fig. 1b) and the adrenals were normal. Histopathological examination showed a neoplasm composed of cell balls, which in turn were made up of rounded cells with abundant eosinophilic cytoplasm. The tumor cells were positive for neuroendocrine markers $\mathrm{CgA}$ and synaptophysin. The surrounding sustenticular cells were positive for S-100. The morphology and immunohistochemical profile were diagnostic of a paraganglioma. The submandibular salivary gland and lymph nodes were also submitted for histology and were negative for metastatic tumor.

\section{Treatment}

After careful explanation, the patient and her family consented to a therapeutic trial of octreotide.

Initially, octreotide was given at a dose of $100 \mu \mathrm{g} 8 \mathrm{~h}$ and, after 1 week off all medications, the plasma NE level had dropped from 50000 to $25000 \mathrm{pmol} / \mathrm{l}$ (Fig. 2) and the CgA level returned to normal (Fig. 3). Having established its potential value, the family consented to the use of octreotide-LA $40 \mathrm{mg}$ every month. This was started together with labetalol $200 \mathrm{mg}$ twice daily to maintain a BP of $<150$ systolic; she was unable to tolerate more than $400 \mathrm{mg}$ labetalol daily. After 3 months, there was considerable clinical improvement with reduced facial pain, tinnitus, sweating, and palpitation, but the patient still required the use of $200 \mathrm{mg}$ labetalol bid.

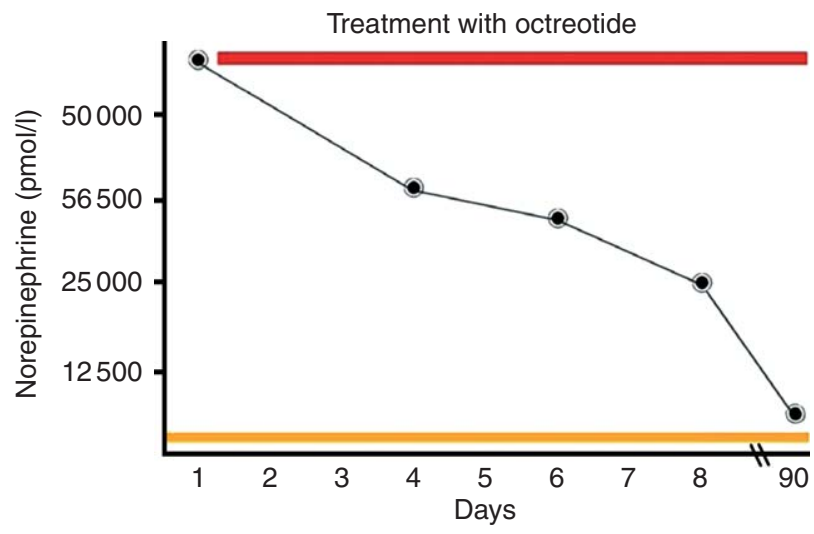

Figure 2

Chromogranin immunohistochemical stain strongly positive in tumor cells. 


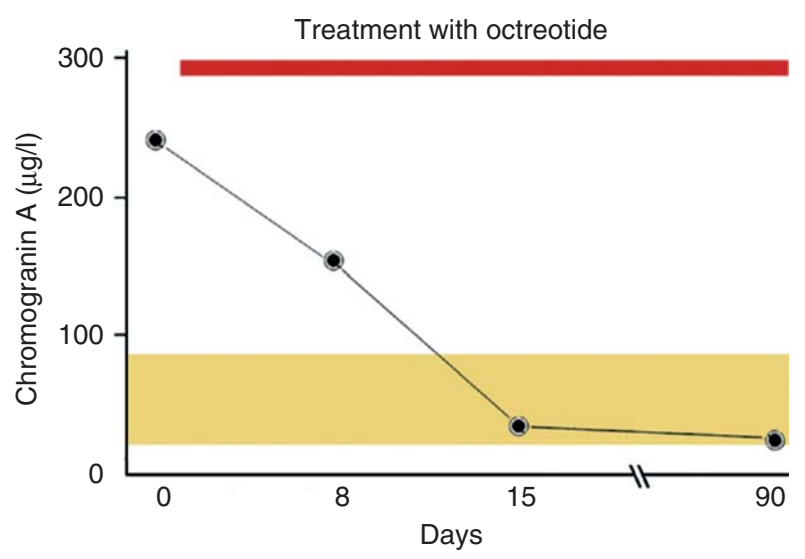

Figure 3

Serum NE levels before and during treatment with octreotide.

The dose of octreotide was therefore increased to $80 \mathrm{mg}$ a month, a dose similar to that which has proved successful in resistant cases of acromegaly (4). She improved dramatically with loss of all her presenting symptoms. Her hearing aid was discarded. The labetalol was reduced to $100 \mathrm{mg}$ bid after 1 month and was stopped three days before tumor embolization with maintenance of a normal BP of $135 / 80$ and a slightly elevated NE level of $5000 \mathrm{pmol} / 1$ (Fig. 2). Blood flow before and after embolization is shown in Fig. $4 a$ and $b$. The surgery was uneventful with only three mild BP spikes occurring during the 10-h procedure when the tumor $5.6 \times 5 \mathrm{~cm}$ was resected completely (Fig. 5).

\section{Outcome and follow-up}

The patient's diabetes throughout her medical treatment still required $100 \mathrm{U}$ insulin daily. Two months after surgery, however, she no longer required insulin and had a normal BP (130/80), CgA, and NE levels. After 21 months, the patient remains completely normal and is taking only indapamide for mild systolic hypertension. (a)

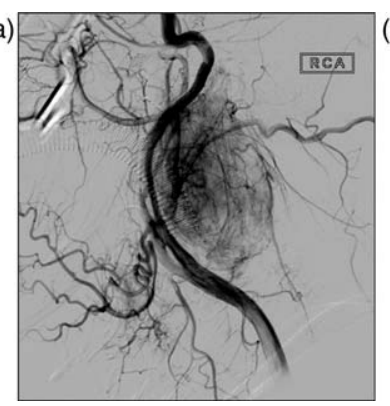

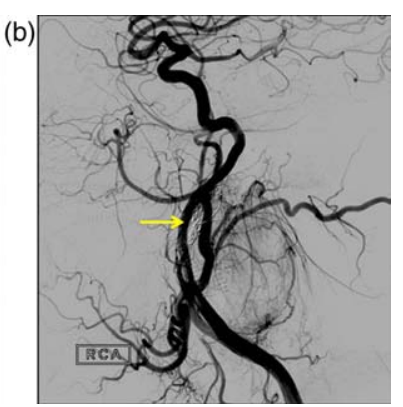

Figure 4

Serum CgA levels before and during treatment with octreotide.
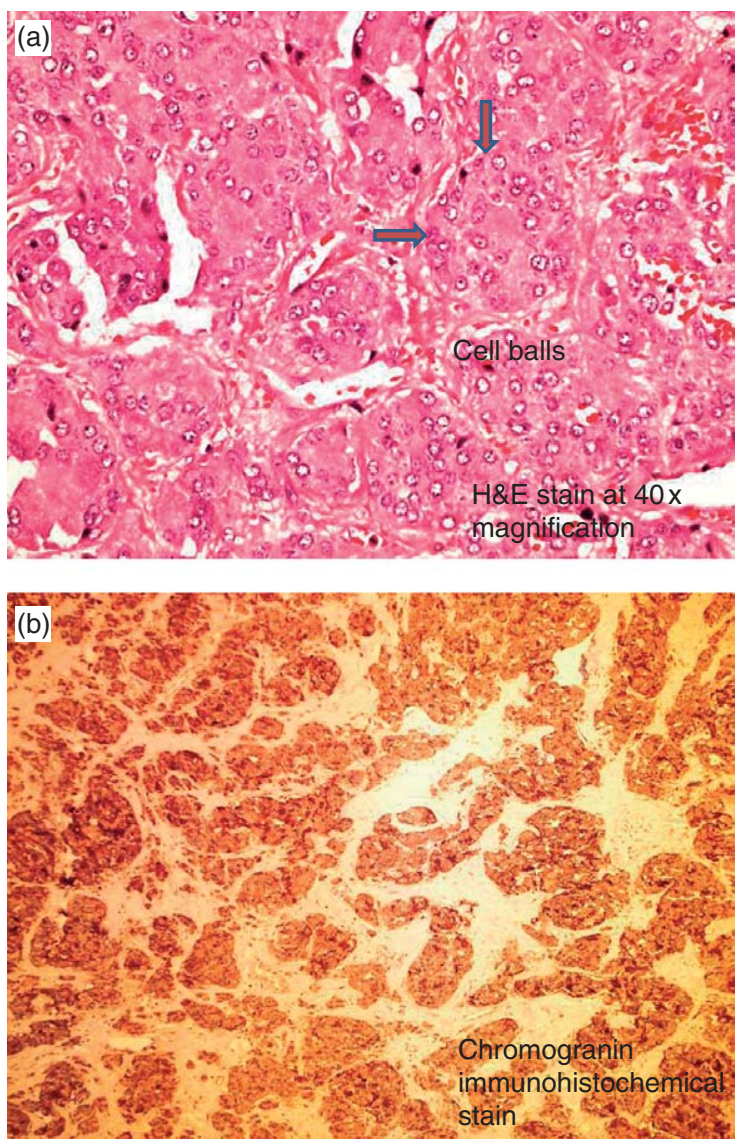

Figure 5

(a) Pre-embolization showing a vascular tumor. (b) Post-embolization showing reduced tumor vascularity.

\section{Discussion}

Paragangliomas are rare neuroendocrine tumors (NETs), the majority of which have receptors for somatostatin and should theoretically respond to treatment with the somatostatin analogue octreotide (5) (6). Although there is abundant literature on the beneficial use of octreotide in patients with NETs in the thyroid gland, the chest, the pancreas, and the gut (7) (8) (9), there are no previous reports of its successful use in the control of the clinical and biochemical abnormalities of patients with CSP. In fact, several publications suggested that it is not useful. Plouin et al. (10) found no significant effect of octreotide on BP or plasma catecholamines when given acutely over a $24-\mathrm{h}$ period. In another study (11), octreotide-LA $30 \mathrm{mg}$ was given monthly for 3 months to eight patients with head and neck paragangliomas. Catecholamine levels were not reported, but two of the 18 tumors shrunk by more than $20 \%$. The authors concluded that octreotide-LA is not useful in the preoperative management of paragangliomas. 
Of considerable interest to us, however, was the authors' observation that the largest reduction in tumor volume occurred in the only patient whose tumor secreted catecholamines.

The patient in this case report had extremely elevated levels of NE (37 times the upper limit). NE levels progressively decreased along with $\mathrm{CgA}$ levels during a short 8 day trial of octreotide (Figs 3 and 4 ). As the patient initially refused to undergo surgery, she was managed with long-acting octreotide every month combined with labetalol. After 3 months, she had improved but still required $200 \mathrm{mg}$ labetalol bid in addition to octreotide in order to maintain a normal BP. We then decided to double her octreotide-LA dose to $80 \mathrm{mg}$ a month.

There was a dramatic clinical response, upon which her labetalol was safely reduced to $100 \mathrm{mg}$ bid. Three days before surgery, labetalol was completely withdrawn with maintenance of a normal BP, normal CgA levels, and a modest elevation of her NE levels. The dose of octreotideLA used by us was prompted by the observation that patients with acromegaly, resistant to conventional doses, subsequently respond to a much higher dose (4). It is also of interest that the patient continued to require large doses of insulin during treatment, presumably because her insulin secretion was inhibited by octreotide. This postulation is supported by the fact that insulin was no longer required for the control of her diabetes after discontinuation of the octreotide, removal of the tumor, and normalization of NE levels. We and others find CgA levels to be of value in the diagnosis and follow-up of patients with pheochromocytomas (12). It is now 21 months since our patient's surgery. She remains normotensive without treatment with a normal CgA $15 \mu \mathrm{g} / \mathrm{l}$.

\section{Declaration of interest}

The authors declare that there is no conflict of interest that could be perceived as prejudicing the impartiality of the research reported.

\section{Funding}

This research did not receive any specific grant from any funding agency in the public, commercial or not-for-profit sector.

\section{Patient consent}

We confirm that we have obtained written informed consent from the patient for publication of the submitted article and accompanying images.
Author contribution statement

O Elshafie, A Almamari, and $\mathrm{N}$ Woodhouse were responsible for the diagnosis and management of the patient throughout treatment and preparation of the manuscript. Y Al Badaai and K Alwahaibi performed the surgery. A Qureshi reported the pathology. S Hussein and F Al Azzri were responsible for performing the imaging and reporting the studies as well as embolization of the tumor.

\section{References}

1 Neumann HP. Phaeochromocytoma. In Harrison's Endocrinology, 2nd edn, pp 133-141, 2010.

2 Telischi FF, Bustillo A, Whiteman ML, Serafini AN, Reisberg MJ, Gomez-Marin O, Civantos FJ \& Balkany TJ 2000 Octreotide scintigraphy for the detection of paragangliomas. Otolaryngology - Head and Neck Surgery 358-362.

3 Hoegerle S, Ghanem N, Altehoefer C, Schipper J, Brink I, Moser E \& Neumann HP $2003{ }^{18}$ F-DOPA positron emission tomography for the detection of glomus tumours. European Journal of Nuclear Medicine and Molecular Imaging 30 689-694. (doi:10.1007/s00259-003-1115-3)

4 Giustina A, Bonadonna S, Bugari G, Colao A, Cozzi R, Cannavo S, de Marinis L, Uberti E, Bogazzi F, Mazziotti G et al 2009 High-dose intramuscular octreotide in patients with acromegaly inadequately controlled on conventional somatostatin analogue therapy: a randomized controlled trial. European Journal of Endocrinology 161 331-338. (doi:10.1530/EJE-09-0372)

5 Erickson D, Kudva YC, Ebersold MJ, Thompson GB, Grant CS, van Heerden JA \& Young WF, Jr 2001 Benign paragangliomas: clinical presentation and treatment outcomes in 236 patients. Journal of Clinical Endocrinology and Metabolism 86 5210-5216. (doi:10.1210/jcem.86.11.8034)

6 Schwaber MK, Glasscock ME, Nissen AJ, Jackson CG \& Smith PG 1984 Diagnosis and management of catecholamine secreting glomus tumours. Laryngoscope 94 1008-1015. (doi:10.1288/00005537198408000-00002)

7 Hearn PR, Reynolds CL, Johansen K \& Woodhouse NJY 1988 Lung carcinoid with Cushing's syndrome: control of serum ACTH and cortisol levels using SMS 201-995 (Sandostatin). Clinical Endocrinology 28 181-185. (doi:10.1111/j.1365-2265.1988.tb03654.x)

8 Johansen K, Reid K \& Woodhouse NJY 1988 Acute ACTH-lowering effect of SMS 201-995 (Sandostatin) in a patient with Cushing's syndrome due to ectopic ACTH-producing lung carcinoid. Saudi Medical Journal 9 513-514.

9 Woodhouse NJY, Dagogo-Jack S \& Ahmed M 1993 Acute and long-term effects of octreotide in ACTH dependent Cushing's syndrome. American Journal of Medicine 95 305-308. (doi:10.1016/0002-9343(93)90283-U)

10 Plouin PF, Bertherat J, Chateiller O, Billaud E, Azizi M, Grouzmann E \& Epelbaum J 1995 Short-term effects of octreotide on blood pressure and plasma catecholamines and neuropeptide $\mathrm{Y}$ levels in patients with phaeochromocytoma: a placebo-controlled trial. Clinical Endocrinology 42 289-294. (doi:10.1111/j.1365-2265.1995.tb01877.x)

11 Duet M, Guichard JP, Rizzo N, Boudiaf M, Herman P \& Tran Ba Huy P 2005 Are somatostatin analogs therapeutic alternatives in the management of head and neck paragangliomas? Laryngoscope $\mathbf{1 1 5}$ 1381-1384. (doi:10.1097/01.MLG.0000165806.99675.A9)

12 Grossrubatscher E, Dalino P, Vignati F, Gambacorta M, Pugliese R, Boniardi M, Rossetti O, Marocchi A, Bertuzzi M \& Loli P 2006 The role of chromogranin A in the management of patients with phaeochromocytoma. Clinical Endocrinology 65 287-293. (doi:10.1111/ j.1365-2265.2006.02591.x)

Received in final form 29 June 2014

Accepted 9 July 2014 